ISSN 1981-416X

Licenciado sob uma Licença Creative Commons

\title{
Profissionais liberais na pós-graduação: motivações e interfaces entre campo profissional e acadêmico
}

\author{
Professionals in graduate studies: Motivations \\ to face a dual work shift and interfaces between \\ the academic and professional fields
}

\section{Gildo Volpato ${ }^{[a]}$, Ione Ribeiro Valle ${ }^{[b]}$, Lucídio Bianchetti ${ }^{[b]}{ }^{*}$}

\author{
[a] Universidade do Extremo Sul Catarinense (UNESC), Criciúma, SC, Brasil \\ [b] Universidade Federal de Santa Catarina (UFSC), Florianópolis, SC, Brasil
}

\section{Resumo}

A presente pesquisa teve como objetivo compreender as motivações dos profissionais liberais vinculados a Programas de Pós-Graduação (PGs) de se manterem nos dois campos de atuação e as possíveis interfaces entre eles. 0 estudo abrangeu 18 profissionais liberais pesquisadores de 11 programas vinculados a cinco universidades comunitárias catarinenses. Foi utilizada a entrevista semiestruturada e na análise foram considerados os princípios da hermenêutica e da dialética, em diálogo com o pensamento relacional de Pierre Bourdieu. As respostas dos participantes revelaram um conjunto de motivações e interfaces que justificam a permanência na dupla jornada de trabalho: o campo profissional é o laboratório dos problemas de pesquisa da Pós-Graduação (PG); relação

*GV: Doutor em Educação, e-mail: giv@unesc.net IRV: Doutora em Ciências da Educação, e-mail: ione.valle@ufsc.br LB: Doutorado em Educação, e-mail: lucidiob@gmail.com 
teoria e prática; satisfação pessoal, profissional e acadêmica; complemento de renda; divulgação dos trabalhos em eventos e reconhecimento por meio de convites e prêmios. Eles apontaram também respaldo e agregação de valor ao profissional liberal no seu campo de trabalho e ao pesquisador na universidade; aplicação dos resultados da pesquisa no campo profissional; ampliação de contatos e parcerias para a realização das pesquisas; atualização, tanto na profissão liberal quanto na academia, e vaidade e marketing pessoal.

Palavras-chave: Profissional Liberal. Pós-Graduação. Motivações Profissionais.

\section{Abstract}

The purpose of this study is to understand why professionals engaged in graduate programs, undertake these two fields of activity and the possible interfaces between them. The study involved 18 professionals who are researchers in 11 programs at five community universities in Santa Catarina. Semi-structured interviews were used and the analysis considered the principles of hermeneutics and dialectics, in dialog with the relational thinking of Pierre Bourdieu. The responses of the participants reveal a set of motivations and interfaces that justify why they face a dual work shift. These include: the professional field serves as a laboratory for the research problems of graduate studies; the relationship between theory and practice; personal, professional and academic satisfaction; a complementary income; promotion of work in events and recognition through invitations and awards; prestige and added value to their professional work and as university researchers; application of research results in their professional fields; expansion of contacts and partnerships for the realization of studies; continuing education, both in the profession and in the academy and; for vanity and personal marketing.

Keywords: Professionals. Graduate studies. Professional Motivations. 


\section{Introdução}

Diante do crescimento do número de matrículas e da acessibilidade na educação superior, decorrentes de políticas públicas e do aumento do número de Programas de Pós-Graduação (PPGs) stricto sensu, houve a necessidade de se recrutar profissionais liberais com titulação de doutorado para atuarem como docentes/pesquisadores nas Instituições de Ensino Superior (IES), atendendo dispositivos da Lei de Diretrizes e Bases da Educação Nacional (LDBEN n 9.394/96).

Muitos profissionais liberais buscaram, também, a carreira acadêmica, e continuaram concomitantemente exercendo as duas atividades profissionais, ou seja, professores pesquisadores, na universidade, e profissionais liberais no mercado de trabalho.

A partir desse cenário é que se definiu como objetivo desta pesquisa compreender as motivações dos pesquisadores vinculados a programas de pós-graduação, que também são profissionais liberais, de se manterem em dupla jornada de trabalho, bem como as interfaces percebidas por eles entre os dois campos de atuação.

A pesquisa abrangeu 18 professores pesquisadores que atuam, também, como profissionais liberais, vinculados a cinco universidades comunitárias catarinenses. A abordagem da pesquisa foi qualitativa e na análise das entrevistas semiestruturadas foram considerados os princípios da análise de conteúdo em diálogo com o pensamento relacional de Pierre Bourdieu.

Os entrevistados são oriundos de diferentes áreas de conhecimento, como saúde, sociais aplicadas e engenharias, e atuam em 11 PPGs diferentes. $O$ tempo de atuação na PG varia entre um e 15 anos. Dos 18 participantes da pesquisa, 13 são homens e cinco são mulheres. Para garantir o anonimato, os entrevistados (E) foram nomeados por números, de E01 a E18, respeitando a ordem alfabética de seus nomes.

Passamos aos referenciais teóricos que embasaram o presente estudo em diálogo com a análise dos dados. 


\section{Aspectos teóricos/conceituais e motivações dos profissionais liberais pesquisadores}

Como o trabalho dos profissionais liberais professores e suas motivações não se limitam a um sistema de relações objetivas, é nas relações dialéticas entre estruturas objetivas, disposições estruturadas e as subjetividades objetivas nas quais elas se atualizam e se reproduzem que se pode conhecê-las. Pierre Bourdieu (1930-2002), pensando a realidade de forma relacional, ensinou a romper com as práticas de pesquisa que consideram por objeto de estudo realidades aparentes, para pensar em termos de relações. E essa é a razão da escolha pela ótica sociológica de Bourdieu, no presente estudo.

$\mathrm{Na}$ sociologia de Bourdieu são centrais a concepção de espaço social, o conceito de campo, de capital e de habitus. No presente estudo foram mobilizados, principalmente, os conceitos de jogo, distinção e illusio para entender o contexto da avaliação da PG e as motivações dos pesquisadores que são também profissionais liberais de se manterem nos dois campos de atuação.

As políticas de avaliação da PG no país têm se intensificado e as exigências acabam por fazer com que os pesquisadores encontrem meios e motivações para serem produtivos, mesmo que isso implique aumento de trabalho diário, diurno, noturno e em finais de semana (VOLPATO; VALLE; BIANCHETTI, 2018).

Isso pode levá-los a fazer concessões, inclusive do seu tempo de lazer, e a entrar num jogo. Parece que a decisão de entrar, permanecer e jogar o jogo é o que faz sentido, pois a busca por produção e a luta por veiculação do conhecimento fazem parte do campo no qual os professores/ pesquisadores atuam, constroem e reconstroem, e este permite lembrar a noção de illusio, que é uma espécie de energia social vital que os leva a disputar os interesses simbólicos produzidos pelo campo, conforme bem definiu Bourdieu (1983).

As relações de poder no campo científico e no campo profissional, apontadas por Bourdieu (1983), acabam se intensificando nesse 
espaço acadêmico. Elas podem ser interpretadas como lutas concorrenciais que ocorrem no interior do campo científico e essas estabelecem relações entre o trabalho de profissional liberal e o de professor pesquisador em programas de PG, considerando possíveis transferências de capitais e ganhos deles decorrentes.

Como acredita Bourdieu (1983), os agentes portadores de um quantum de capitais, sejam culturais, sociais, científicos, políticos, econômicos ou de outra natureza, estão continuamente contestando e ou aceitando diretrizes que redefinem as bases da sociedade. E essas interferências, essas lutas concorrenciais, ocorrem também na universidade enquanto instituição social que congrega agentes que atuam em campos de natureza diferenciada, mesmo sendo todos professores pesquisadores.

$\mathrm{E}$, nessas condições, torna-se impossível não viver num universo quase mágico sem ser totalmente possuído por ele, pelo domínio de um illusio específico, isto é, sem ter interesse, sem entrar em concorrência, sem desenvolver estratégias de conquista do capital específico desse universo. Afinal, como afirmou Bourdieu (1996a, p. 139),

a illusio é estar preso ao jogo, preso pelo jogo, acreditar que o jogo vale a pena [...] dar importância a um jogo social, perceber que o que se passa aí é importante para os envolvidos, para os que estão nele. Interesse é "estar em", participar, admitir, portanto, que o jogo merece ser jogado e que os alvos engendrados no e pelo fato de jogar merecem ser perseguidos; é reconhecer o jogo e os alvos.

Bianchetti, Valle e Pereira (2015, p. 95) apresentam uma reflexão pertinente sobre este aspecto:

Presos uns aos outros pela concorrência, inteiramente envolvidos na disputa por classificação e distinção acadêmicas (expressas pelo ranking de credibilidade), os pesquisadores encontram na luta entre parceiros-adversários a razão social de existir, motivo pelo qual são cúmplices ou, no mínimo, coniventes - o mais das vezes involuntários - das coerções que os submetem e os enquadram. 
Nesse aspecto torna-se importante recorrer ao conceito de campo de Bourdieu (2004a, p. 20) "para designar esse espaço relativamente autônomo, esse microcosmo dotado de suas leis próprias" que no plano simbólico "se situa ao nível do ritual, não colocando em causa os princípios de poder que estruturam o campo" (BOURDIEU apud ORTIZ, 1983, p. 23).

Para Bourdieu (2017, p. 70),

o campo universitário reproduz na sua estrutura o campo do poder cuja ação própria de seleção e de inculcação contribui para reproduzir a estrutura. É na verdade no e por seu funcionamento como espaço de diferentes entre posições (e, da mesma maneira, entre as disposições de seus ocupantes) que se realiza, fora de toda intervenção das consciências e das vontades individuais ou coletivas, a reprodução do espaço das posições diferentes que são constitutivas do campo do poder.

Por isso, segundo ele, o campo científico "é um campo de forças dotado de uma estrutura, e também um campo de lutas para conservar ou transformar esse campo de forças" (BOURDIEU, 2001, p. 69).

Um cientista faz a pesquisa que ele considera importante, mas a satisfação intrínseca e o interesse não são as únicas motivações, como afirma Bourdieu (1983). Se assim fosse o pesquisador não ficaria tão transtornado ao descobrir uma publicação com os resultados aos quais ele estava quase chegando, ainda que o interesse intrínseco de seu trabalho não tenha sido atingido. Para o autor, isso ocorre porque o trabalho do pesquisador não deve ser interessante somente para ele, mas deve também ser importante para os outros. Neste sentido:

O que é percebido como importante e interessante é o que tem chances de ser reconhecido como importante e interessante pelos outros; portanto, aquilo que tem a possibilidade de fazer aparecer aquele que o produz como importante e interessante aos olhos dos outros (BOURDIEU, 1983, p. 125).

Tudo indica que a Coordenação de Aperfeiçoamento de Pessoal de Nível Superior (CAPES) no seu processo de avaliação faz com que seus 
agentes, neste caso os pesquisadores das diferentes áreas, acabem desenvolvendo habitus comuns. Habitus para Bourdieu (apud ORTIZ, 1983, p. 15) se refere a um "sistema de disposições duráveis, estruturas estruturadas predispostas a funcionarem como estruturas estruturantes". Para ele, “o habitus se sustenta, [...] através de 'esquemas generativos' que por um lado antecedem e orientam a ação e, por outro, estão na origem de outros 'esquemas generativos' que presidem a apreensão do mundo enquanto conhecimento" (p. 16).

No entanto, como afirmam Bianchetti, Valle e Pereira (2015, p. 48),

se o campo científico submete-se à tirania de uma norma ou de uma ordem, subordina, de forma deliberada ou sob a força de mecanismos coercitivos, suas finalidades acadêmicas a finalidades práticas, seus critérios científicos a critérios normativos, correndo o risco de limitar a produção científica a "competências estratégicas, a demandas ad hoc".

De certa forma, trata-se de uma luta simbólica, como afirma Valle (2007), na medida em que visa à produção de sentidos comuns e revela a posição específica do estado, que dispõe do monopólio da dominação legítima e, nessa condição, procura inculcar uma definição também legítima do mundo social.

Bourdieu (1997, p. 3) fala que "obedecemos bem além dos limites nos quais se exerce a coerção do Estado. Obedecemos sem sofrer coação direta e mesmo nas condições em que toda coerção potencial, ou virtual está ausente" ${ }^{1}$. Para ele, "é como se, embora em postos separados, estivéssemos no mesmo campo, sendo coniventes e, embora adversários, cúmplices" (BOURDIEU, 1983, p. 63).

Percebe-se que estamos lidando com agentes que exercem atividades profissionais prestigiosas não apenas na universidade, mas

1 Tradução para o português realizada por lone Ribeiro Valle. Transcrição e edição do documento audiovisual registrado em francês pelo Service Audiovisuel de l'Université de Rouen, com o título "La Domination", realizadas por Charles Soulié. Conferência, ou "Lição descentralizada", proferida por Pierre Boudieu na Universidade de Rouen, no dia 26 de novembro de 1997. 
também como profissionais liberais no mercado de trabalho, embora eles se inscrevam em muitos outros quadros sociais, privados ou públicos, duráveis ou efêmeros.

Quando um profissional do mercado de trabalho passa a exercer a atividade docente, seu habitus de profissional liberal e o habitus acadêmico se entrecruzam na sua prática pedagógica, havendo alguns ganhos na transposição do habitus de professor para o mercado de trabalho e vice-versa. Quando esses profissionais transitam no mercado de trabalho e no campo acadêmico, há uma interação entre os dois campos, trazendo ganhos para esses profissionais (BUONICONTRO, 2003).

Como nos propomos a compreender as razões e interfaces entre campo profissional e acadêmico, os entrevistados nos falaram sobre suas reais motivações de permanecer nas duas jornadas de trabalho.

A partir do quadro de análise das respostas dos entrevistados foi possível elencar dez razões ou motivações, que podem ser identificadas no quadro 1, abaixo, em ordem decrescente de número de repetições:

Quadro 1 - Razões ou motivações para manterem-se na PG e na profissão liberal

\begin{tabular}{|ll|}
\hline \multicolumn{1}{|c|}{ Razões ou motivações } & Número \\
\hline O campo profissional é o laboratório dos problemas de pesquisa da PG & 15 \\
\hline Ampliação das possibilidades de estabelecer a relação teoria e prática & 10 \\
\hline Satisfação pessoal/prazer profissional & 09 \\
\hline Complemento de renda & 07 \\
\hline Reconhecimento por meio de convites, publicações e prêmios & 06 \\
\hline Respaldo/agrega valor no campo profissional e na universidade & 05 \\
\hline Possibilidade de aplicação dos resultados da pesquisa no campo profissional & 05 \\
\hline Ampliação de contatos e parcerias para a realização das pesquisas & 03 \\
\hline Manter-se atualizado/na ponta do conhecimento & 02 \\
\hline Vaidade/marketing pessoal & 01 \\
\hline
\end{tabular}

Fonte: Elaborado pelos autores, a partir dos dados da pesquisa. 
O campo profissional é o laboratório dos problemas de pesquisa da $P G$ foi o motivo citado por 15 entrevistados para justificar a importância de continuar atuando na profissão liberal, além da vida acadêmica. $\mathrm{O}$ fato de permanecerem como profissionais liberais lhes favorece na medida em que trazem para a academia as questões-problema que vivenciam. Foram muitos os depoimentos que são dados empíricos que nos dão segurança de fazer esta assertiva:

Muitas coisas que a gente aprende, a gente vê lá. Dificilmente eu teria oportunidade de conhecer se eu não estivesse lá dentro, trabalhando na área. Eu vejo um campo que tem sido pouco explorado, pois eu tenho certeza que existe uma gama de possibilidades de pesquisas para explorar, que eu posso fazer pegando as coisas de lá do campo profissional, que dê para eu pesquisar, fazer publicações, porque muitas coisas não têm quase publicação (E03)

Algumas coisas que me incomodavam ou que me interessavam acabam surgindo por conta da área fora da academia. Então as temáticas são trazidas como um problema ou como um interesse e venho para a academia e pesquiso. [...]. Na área de marketing, [...], alguns periódicos internacionais não aceitam mais pesquisa feita somente em sala de aula, pesquisa feita só na universidade. 'Não, não aceitamos mais', já de imediato no escopo do periódico falam isso. Se tu pegar nos periódicos principais avaliados pela CAPES, vais perceber. Isso é constante (E05)

Percebe-se que se mantendo nas duas frentes de trabalho encontram material empírico, substratos e temas para o desenvolvimento de suas pesquisas, o que potencializa o alcance das metas de produção exigidas na avaliação da CAPES.

Nossos entrevistados são professores em disciplinas na graduação e na PG stricto sensu. Por isso dez deles destacaram como razão para permanecer em ambas as atividades a ampliação das possibilidades de estabelecer a relação teoria e prática. A presente pesquisa ratifica o estudo de Volpato (2010) de que trazer experiências do campo profissional para a sala de aula é uma característica da atuação do profissional liberal professor. Vejamos o que disseram: 
Jamais conseguiria falar com a mesma propriedade e confiança do que é certo ou errado, se eu não tivesse vivenciado a área pública, se eu não tivesse vivenciado uma instituição como o SEBRAE, se eu não tivesse o histórico de ter trabalhado lá, onde houve essa mudança cultural do que é uma pequena empresa e a importância dela. Então, é diferente. Se eu tivesse ficado na academia, não era a mesma coisa (E07)

Não só o meu discurso se reforça na prática clínica, porque eu estou aqui na $P G$, mas o meu discurso aqui dentro da universidade é reforçado pela prática clínica, porque eu trago comigo a experiência do dia a dia, que é aquela questão do tratar as pessoas, na área da saúde. Isso é muito importante, você precisa ter a vivência do cuidado, do cuidado humanizado, da prática, e isso eu trago para os meus alunos aqui de graduação e de pós também (E10)

Eu vou dar uma aula aqui, eu vou ilustrar as coisas com coisas que eu vejo lá, não é uma coisa que é, é algo que eu faço. Não é uma coisa que eu li num livro ou li num artigo. As coisas são coisas que eu faço, vivo. É muito interessante para mim e para os alunos também é interessante (E03)

Os depoimentos acima mencionados, embora sejam de profissionais da área de ciências sociais aplicadas e da saúde, encontram ressonância também com os achados de Buonicontro (2003, p. 12), ao pesquisar profissionais liberais professores da área das engenharias:

Quando o engenheiro passa a exercer as atividades docentes, o habitus do engenheiro e o habitus acadêmico se entrecruzam na sua prática pedagógica, havendo alguns ganhos na transposição do habitus de professor para o campo da engenharia e vice-versa. Quando os engenheiros-professores transitam pelo campo da engenharia e pelo campo acadêmico, há uma interação entre os dois campos, trazendo ganhos para esses profissionais.

A satisfação pessoal/prazer profissional também foi mencionada por nove entrevistados, o que demonstra que muitos deles têm clareza do quanto essas atividades são importantes em suas vidas. Vejamos algumas falas: "A academia eu tenho prazer nela, por si só" (E18). "Eu acho que é paixão mesmo, é difícil explicar, é gratificação" (E02). "O Stricto Sensu para mim 
hoje é o principal. Mas lá é aquele prazer de estar tratando o paciente" (E04), (E08). "Os dois são como cachaça, quando você experimenta, tu queres sempre tomar um pouquinho" (E12).

Faz-se necessário registrar que o gosto e o prazer geralmente se encontram relacionados ao alcance das exigências de publicação, a citação do nome dos entrevistados em eventos e revistas, ou seja, ao reconhecimento de suas habilidades e competências, a distinção, tanto no campo profissional quanto na universidade.

A oportunidade de obter um complemento de renda também foi citada por sete entrevistados. Embora relativizassem que a decisão de se manterem nas duas atividades era financeira, admitiram que "pesa" na decisão. "Não é só questão financeira, mas a questão financeira, lógico, contribui, ajuda" (E01). "Lá eu não largo porque é mais uma renda que entra, não é só isso, mas isso é uma coisa a ser considerada" (E04). "Eu considero a financeira, lógico, tem esse aspecto" (E07).

Percebe-se, pelos seus depoimentos, que o valor financeiro não é o único motivo, e nem parece ser o maior, pois as manifestações sobre o complemento de renda não apareceram como único motivo para nenhum deles. Bourdieu (2004b, p. 31) ajuda a compreender esse aspecto:

essa forma particular de illusio que é o interesse científico, ou seja, um interesse que em relação às formas de interesse correntes na existência cotidiana (e em particular no campo econômico) aparece como desinteressada, gratuita. Mas, mais suficiente o interesse "puro", desinteressado, é um interesse pelo desinteresse, forma de interesse que convém a todas as economias dos bens simbólicos, economias antieconômicas, nas quais, de alguma maneira, é o desinteresse que "compensa".

Os entrevistados que estão em início de carreira, tanto na profissão liberal quanto na docência, foram os que mais falaram, na entrevista, da família e dos filhos pequenos, talvez porque sentem mais necessidade de se submeterem a dupla jornada de trabalho, por maior dependência de questões econômico-financeiras. 
Sublimação que, tacitamente, exigida de todo recém-chegado, é implicada nessa forma particular de illusio inerente ao pertencimento a um campo, isto é, a crença científica como interesse desinteressado e interesse pelo desinteresse, que leva a admitir, como se diz, que o jogo científico merece ser jogado, que ele vale a pena, que define os objetos dignos de interesse, interessantes, importantes, capazes, portanto, de merecer o investimento (BOURDIEU, 2004b, p. 30).

O reconhecimento por meio de convites, publicações e prêmios também foi considerado uma razão para continuarem nas duas atividades profissionais. $\mathrm{O}$ fato de estarem na universidade e terem méritos tanto nas pesquisas que realizam no âmbito da PG quanto na atuação no campo profissional fortalece seus argumentos em eventos acadêmicos e na profissão liberal. Segundo Valle (2010, p. 40),

o mérito só tem sentido numa sociedade que valoriza algumas capacidades mais do que outras, não sendo nem transparente, nem neutro, como se estima. Além disso, ele não é facilmente mensurável, nem pode ser identificado a priori, pois só se sabe o que cada um merece depois de ver o que conseguiu.

Este reconhecimento baseado no mérito foi considerado por seis entrevistados. "Não há dúvida nenhuma que quando eu falo, quando eu mostro o que eu já recebi de premiação externa e tal, isso dá um respaldo" (E05). "Gosto muito quando saem pesquisas, o teu trabalho é publicado e premiado num congresso. Eu tenho muita satisfação na vida acadêmica, porque a gente sente que se dedica, mas tem uma gratificação que retorna" (E16).

Eu acabo sendo convidado muito na nossa área para fazer palestras nos congressos brasileiros de análises clínicas, por exemplo. E aí os colegas acabam vendo que é a gente que está lá falando e depois vêm conversar, "qual é o método que tu estás usando lá dentro do laboratório?" (E02).

Esta condição assegura-lhes um lugar de prestígio, de distinção na área e na universidade. Disse Bourdieu (2017, p. 134): "Uma vez X me convidou a ir a L para fazer uma conferência, o que me proporcionou 
quatrocentos ou quinhentos pau. Não é isso que é interessante, mas isso se torna interessante para encontrar um posto".

Segundo Bourdieu (2013), em todas as organizações sociais existem os agentes distintos e os outros. A partir dessas constatações, as perguntas que ele faz são as seguintes: o que e quem define o agente distinto? Como se constrói distinto? E os outros onde se enquadram socialmente? Como ocorre esse jogo entre o distinto e o não distinto? Um dos entrevistados, da área da saúde, reporta-se à questão da distinção, quando fala da importância da visibilidade da sua publicação:

Eu não tenho o mesmo estímulo que eles têm para emplacar publicações A1, $A 2$, por exemplo, na CAPES, porque tenho interesse muito maior dentro da minha especialidade. Se eu pegar uma revista de alto nivel de impacto na minha especialidade, na CAPES pode representar pouco, ou não conta. Por exemplo: eu tenho uma publicação na Revista da Federação Pan-Americana da Saúde, que é A1, mas ninguém sequer sabe. Honestamente não me interessa se é $A 1$, se ninguém dentro da minha especialidade lê (E08).

Como afirma Bourdieu (1996b), baseado em uma metafísica da distinção, para ser o centro das atenções devemos ser reconhecidos como distintos, de valor, devemos ter alguma honra e dignidade frente a nós mesmos e aos demais. As instituições, ou os campos, através de prêmios e destaques, "conseguem fazer crer aos indivíduos consagrados que eles possuem uma justificação para existir, ou melhor, que sua existência serve para alguma coisa" (BOURDIEU, 1996b, p. 106).

Proclamados como dignos de tal honraria e autorizados a receberem os lauréis da glória estarão aqueles que melhor vivenciarem esse jogo como algo sério, efetivo, no mais alto grau de adesão possível. Mas o jogo é compensado na medida em que o agente se percebe valorizado, seja pela CAPES ou pelos pares.

O fato de serem professores universitários, pesquisadores da PG, e continuarem atuando como profissionais liberais lhes dá respaldo/agrega valor no campo profissional e na universidade. Isso acontece 
independentemente da área de atuação, pois, como afirmaram Bianchetti, Valle e Pereira (2015, p. 60),

o que se vê hoje, em virtude da dinâmica do campo científico, estendeu-se a todas as demais áreas, independentemente das lógicas específicas de produção de conhecimento que cada uma possui, isto é, independentemente dos domínios epistemológicos próprios aos diversos ramos da ciência.

Esta razão ou motivação foi relatada por cinco entrevistados: "Eu vejo que quando eu falo uma coisa, 'ah, lá no banco é assim', abre o olho, porque eles estão vendo que aquilo que eu falo não é só uma coisa que está escrito num livro. É uma coisa que acontece na empresa e que eu vivencio" (E03). "Quando eles sabem que eu também trabalho fora da academia, isso dá um respaldo, uma garantia, uma segurança neles: - esse cara está falando coisa com coisa" (E05).

\section{E mais:}

Agrega tu estar na academia e estar no mercado, ajuda os dois. Discutir com o profissional que tem essa bagagem científica é diferente. Inclusive a gente é procurado e interage com outros colegas profissionais, também médicos, enfermeiros, fisioterapeutas, como referência para tirar dúvidas. $O$ relacionamento deles com a gente é outro, pelo fato de ter uma bagagem científica. Inclusive os grandes laboratórios internacionais de análises clínicas têm como diretores técnicos ou chefes profissionais que são professores nas universidades, que têm esse pé na academia. Senão tu não tens muita chance de subir na hierarquia da empresa (E02).

Embora essa motivação apareça separada da anterior, ela contém, em sua essência, os mesmos elementos de análise, baseada na metafísica da distinção, pois, como mostra Bourdieu (1996b), sentimos necessidade de sermos reconhecidos como distintos dos outros, devemos ter alguma honra e valor frente a nós mesmos e aos demais. 
Outra razão apresentada por quatro entrevistados como motivação para permanecer em ambas as atividades foi a possibilidade de aplicação dos resultados da pesquisa no campo profissional:

Alguns exames laboratoriais de função renal nós não fazíamos direito. Por eu ter acesso a esse background científico a gente acabou trazendo para a nossa rotina no laboratório no mercado. Eu sempre busco trazer essas coisas para a rotina, que impactam a rotina também, não só do nosso laboratório, mas que acaba sendo disseminada para os outros. (E02).

A gente publicou um artigo sobre os beneficios da semente de sucupira. Levamos lá, para as mulheres da pastoral da saúde, para mostrar o efeito anti-inflamatório, e isso repercutiu bastante para os médicos que atendiam lá também. Botaram o artigo na Pastoral e foi interessante, porque eu, atendendo pacientes com dor que não gostam de tomar remédio e eu falo"olha, a senhora pode ir lá no Pastoral da Saúde. Com cinco reais o senhor compra a tintura da Pterodon pubenscens Benth, que é a sucupira, e você vai tomar que vai melhorar" (E04).

Essa imbricação entre empresa e academia pode ser positiva e potencializar alcances sociais importantes, dependendo da área ou campo de atuação. Nos casos aqui analisados, pelo conteúdo dos depoimentos, nota-se que o compromisso e o alcance social dos resultados das pesquisas acabaram se tornando um bem público, coletivo, mais do que simplesmente gerando publicações com vistas a atender a avaliação da CAPES ou gerando ganhos financeiros. No entanto, como diz Bourdieu (2001, p. 78): "Se há um lugar onde se pode supor que os agentes agem em conformidade com intenções conscientes e calculadas, segundo métodos e programas conscientemente elaborados, esse lugar é o campo científico".

Também foi citada por três entrevistados a possibilidade de ampliação de contatos e parcerias para a realização das pesquisas, como motivos de se manterem na dupla jornada de trabalho. Em tempos de escassos recursos para a realização de pesquisas, esse é um caminho promissor para algumas áreas. 
Importante considerar que este aspecto também está contemplado na avaliação da CAPES, e os impactos devem ser sociais no sentido lato, pois é de se imaginar que há conhecimento de que a "transformação de invenções científicas em inovações geradoras de novos produtos [é também geradora] de novos lucros no mundo econômico" (BOURDIEU, 2004a, p. 54).

Nem sempre as vantagens são ganhos financeiros diretos, mas as parcerias podem prover ideias ou temas de pesquisa, espaços físicos, equipamentos e insumos necessários à investigação. Vejamos um depoimento:

Os contatos fora nos permitem desenvolver muitos trabalhos acadêmicos. Os projetos de pesquisa que eu tenho, fora um com a FAPESC, são em parceria com empresas. Graças a esses contatos a gente consegue fazer essa integração boa. Tive vários alunos que já trabalharam nesses projetos, desde o estágio da graduação, TCC, de dissertações (E11).

$\mathrm{Na}$ falta de recursos da universidade, é importante considerar o alerta de Bianchetti, Valle e Pereira (2015, p. 61):

Os profissionais altamente produtivos dessas áreas encontram nesse sistema um poderoso estímulo, principalmente no que concerne ao financiamento de suas pesquisas. Além disso, a eventual proximidade com o setor econômico e o fomento governamental à inovação e ao registro de patentes conduzem esses pesquisadores ao incremento da produtividade científica em razão dos retornos materiais potencialmente disponíveis na interface entre ciência e o mundo da produção e dos negócios.

No caso desta pesquisa, os resultados apontam que a busca por parcerias na obtenção de recursos é com vistas ao alcance social, coletivo mais do que o particular, o que evidencia que nem toda pesquisa financiada por empresas ou instituições privadas é mercadológica ou promíscua na obtenção e usos dos resultados. Deve ser analisado o motivo-fim e o resultado dessas parcerias. 
Manter-se atualizado/na ponta do conhecimento foi mencionado como razão de dois entrevistados por considerarem que o fato de estarem nas duas pontas, academia e profissão liberal, obriga-os a estar sempre atualizados: "Se eu não me mantiver lá no campo profissional e aqui vai ficar difícil de eu me atualizar" (E09).

As razões de se manterem nas duas frentes profissionais parecem estar associadas à clareza de que a atualização é fundamental para potencializar a atuação e o domínio no campo profissional e na atividade acadêmica, sobretudo na de pesquisador da PG. Também pode estar relacionado às relações de poder e à busca pela distinção, apontadas por Bourdieu (1983).

A vaidade/marketing pessoal apareceu como razão de se manter em ambas as atividades apenas por um dos entrevistados, o que não significa dizer que outros não possam ter este motivo; no entanto não mencionaram. Assim ele disse: "Me manter na pesquisa, é vaidade. Porque pesquisa não dá dinheiro. A primeira vez que eu publiquei numa revista, que eu ganhei um editorial, eu dava pulo de alegria. O que eu faço é um pouco de marketing pessoal" (E15).

Este motivo, também, está relacionado à busca e à necessidade da distinção que são evidenciadas nas lutas concorrenciais dentro do campo, na universidade e na profissão liberal, como já abordado.

Este estudo mostrou que há um conjunto de motivações para os professores/pesquisadores continuarem exercendo as duas atividades profissionais, mesmo com a pressão advinda das avaliações a que estão submetidos. Nenhum dos entrevistados mencionou um motivo único de permanecer em ambas as jornadas de trabalho, mas vários deles relacionados às circunstâncias diversas que os levaram a essa condição.

Em alguns casos o motivo inicial de entrada na universidade e no universo da PG pode ter sido melhorar a renda familiar, mas à medida que se envolveram com a vida acadêmica perceberam a importância da experiência na prática profissional, seja para a pesquisa ou para o estabelecimento de uma relação teoria e prática coerente e orgânica entre as 
duas atividades, reconhecida por seus alunos, o que lhes exige esforços extras, boas escolhas, otimização e organização do tempo.

Em síntese, o entrecruzamento de motivações pela dupla jornada de trabalho se deu da seguinte forma: porque o campo profissional é o laboratório dos problemas de pesquisa da PG; pelas possibilidades de estabelecer a relação teoria e prática; pela satisfação pessoal/prazer profissional; pelo complemento de renda; pela possibilidade de divulgação dos trabalhos em eventos e reconhecimento por meio de convites e prêmios. Eles apontaram também respaldo e agregação de valor ao profissional liberal no seu campo de trabalho e ao professor pesquisador na universidade; a possibilidade de aplicação dos resultados da pesquisa no campo profissional; a possibilidade de ampliação de contatos e parcerias para a realização das pesquisas; o fato de manter-se atualizado, na ponta do conhecimento tanto na profissão liberal quanto na academia, e por vaidade e marketing pessoal.

Quanto às interfaces entre esses dois mundos que convergem, tensionam e se complementam, são muitas e demonstram a complexidade em que estão imbricadas com as motivações de continuarem na dupla jornada de trabalho. Da mesma forma evidencia-se, uma vez que eles percebem no campo profissional o maior potencial de suas pesquisas e publicações, que os critérios de avaliação da CAPES acabam sendo o grande motivador de permanecerem nas duas atividades.

\section{Considerações finais}

Nossos entrevistados, conscientemente ou não, estão permanentemente participando de lutas concorrenciais no campo científico no âmbito da PG e na universidade, por meio de produções acadêmicas, patentes, publicações, palestras, conferências, etc., e também em relação aos seus pares no trabalho como profissionais liberais. Esses pesquisadores vivem o dilema de atender a avaliação da CAPES e encontram no 
campo profissional, embora exigindo sacrifícios extras, o laboratório de seus achados e reflexões teóricas.

E é nesse cenário que nossos entrevistados nos proporcionaram compreender o quanto é complexo o campo acadêmico, o universo da pesquisa e como somos movidos por sentimentos internos, de necessidade de reconhecimento e distinção e por pressões externas do campo profissional e da avaliação da CAPES.

\section{Referências}

BIANCHETTI, L.; VALLE, I. R.; PEREIRA, G. R. M. O fim dos intelectuais acadêmicos? Induções da CAPES e desafios às associações científicas. Campinas: Autores Associados, 2015.

BOURDIEU, P. O campo científico. In: ORTIZ, R. (org.). Sociologia. São Paulo: Ática, 1983.

BOURDIEU, P. Razões práticas: sobre a teoria da ação. Campinas: Papirus, 1996a.

BOURDIEU, P. A economia das trocas lingüísticas. São Paulo: Edusp, 1996b.

BOURDIEU, P. La Domination. Conference à l'Université de Rouen. 26 nov. 1997.

BOURDIEU, P. Contrafogos 2: por um movimento social europeu. Rio de Janeiro: Zahar, 2001.

BOURDIEU, P. Esquisse pour une auto analyses. Paris: Raisons d'Agir, 2004a.

BOURDIEU, P. Os usos sociais da ciência. Por uma sociologia clínica do campo científico. São Paulo: Editora da UNESP, 2004b.

BOURDIEU, P. A distinção: crítica social do julgamento. 2. ed. Porto Alegre, RS: Zouk, 2013.

BOURDIEU, P. Homo Academicus. 2. ed. Trad. Ione Ribeiro Valle e Nilton Valle. Florianópolis: Editora da UFSC, 2017. 
BRASIL. Lei no 9.394, de 20 de dezembro de 1996. Estabelece as diretrizes e bases da educação nacional. Brasília, 1996.

BUONICONTRO, C. M. S. A teoria de Bourdieu: os conceitos utilizados no estudo do processo de construção da prática pedagógica do engenheiro-professor. Revista de Ensino de Engenharia, Brasília, v. 22, n. 1, p. 7-13, 2003.

ORTIZ, R. (org.). Sociologia. São Paulo: Ática, 1983.

VALLE, I. R. A obra do sociólogo Pierre Bourdieu: Uma irradiação Incontestável. Educação e Pesquisa, São Paulo, v. 33, n. 1, p. 117-134, jan./abr. 2007.

VALLE, I. R. Justiça escolar: das desigualdades justas à igualdade sem adjetivos! In: VALLE, I. R.; GASPAR, V. L.; DAROS, M. D. (orgs.). Educação escolar e justiça social. Florianópolis: NUP, 2010.

VOLPATO, G. Profissionais liberais professores: Aspectos da docência que se tornam referências na educação superior. Curitiba: Editora CRV, 2010.

VOlPATO, G.; VAlLE, I. R.; BIANCHETTI, L. Profissionais liberais e PósGraduação: percepções e estratégias em relação à avaliação da CAPES. Revista Impulso, Piracicaba, v. 28, n. 71, p. 61-77. jan./abr., 2018.

Recebido: 15/07/2018

Received: 07/15/2018

Aprovado: 26/09/2018 Approved: 09/26/2018 